\title{
EFFECTS OF RESIDUAL BIOMASS USE IN AGRICULTURE
}

\author{
M. Pavlova* \\ Department of Agrarian Economy, University of Economics - Varna, Varna, Bulgaria
}

\begin{abstract}
The present-day agriculture produces large amounts of waste biomass from its activity which is not being remade. The utilization of waste biomass helps in reducing the negative impact of the sector on the environment and improves the economic results for the farms.

The purpose of this report is to outline the impact of the sector on the environment, to draw the unutilized potential of raw materials from the sector and to present the effects of their processing. A conceptual model was developed for the needs of the report, where a stock-breeding farm in the town of Tvarditsa uses the waste material from its activity for biogas production in a cogeneration installation of electricity and heat. The results show the reason of the use of residual biomass to cover the farm's own heat and electricity needs, as well as a residual high-quality biocompost that the farm can use for its own farmland or sell to other plant-growing farms. Ehe efficient use of waste biomass in the sector is a prerequisite for a more sustainable development of the sector.
\end{abstract}

Key words: potential of waste biomass, biogas, effects of waste biomass processing

\section{INTRODUCTION}

The achievements in scientific and technical progress make it possible to increase the volume and quality of agricultural production as well as its efficiency and allow the introduction of high-quality equipment, production and use of fertilizers, chemical and biological agents for plant pests control. A number of scientists share their view that intensification in agriculture has led to unfavorable consequences for nature. Exactly these unfavorable consequences express in concrete form to the depletion and overburdening of the soils, the occurrence of water and wind erosion, high energy intensity, pollution of the environment, deterioration of the quality of agricultural production, territorial overconcentration and specialization of production, etc. (1). The history brings to our knowledge that with every major civilization, when its soil was fertile, it had a thriving farm economy, but later, in parallel with the irrational use of soils, much of the fertile farmland was salted and turned into deserts. Pessimistic is the picture related to the Bulgarian land resources as well. Studies (2-5) clearly show that not a small part of

\footnotetext{
*Correspondence to: Monika Pavlova, University

of Economics - Varna, Department of Agrarian

Economy, Bulgaria, Adress: str. Tintqva 6, ap.20,

Phone: 0885015229, e-mail:

monika.anastasova.pavlova@gmail.com
}

our most fertile lands are physically damaged or completely destroyed agricultural lands where the whole soil layer is destroyed, agricultural lands are with degraded soils etc.

\section{Effects on the environment caused by modern agriculture.}

The effects of the application of chemicals for the production caused by the intensification of modern agricultural production also entail some clear ecological problems, which are divide in such ecological problems that arise from the use of mineral fertilizers in economic activity as well as problems arising from the use of chemical preparations for plant protection. Consequences of the intensive use of chemical fertilizers and plant protection products are the pollution of surface and groundwaters with nitrates, the increase in nitrate content above the maximum admissible concentrations in the produced products, on which subsequently humans and animals live and it is a threat to their health, temporary or permanent damage to soil fertility, acidification of soils, frequent and intensive use of chemical preparations leads to resistance in plants and a number of other negative consequences. Agricultural activity has the task to feed the evergrowing population or the so-called food problem. The sector's current decision is linked to an intensification of the 
production activity, which in its turn leads to inefficient results for the current production and the state of the environment. There is a observed tendency of increasing the input of synthetic fertilizers and plant protection products, a source of a number of serious pollutants for the environment and water (Table 1).

Table 1. Use of inorganic fertilizers in tons

\begin{tabular}{|c|c|c|c|c|c|c|c|c|c|c|}
\hline Year & 2006 & 2007 & 2008 & 2009 & 2010 & 2011 & 2012 & 2013 & 2014 & 2015 \\
\hline EC-28 & $\begin{array}{c}10817 \\
245\end{array}$ & $\begin{array}{c}10877 \\
612\end{array}$ & $\begin{array}{c}11050 \\
533\end{array}$ & $\begin{array}{c}9948 \\
116\end{array}$ & $\begin{array}{c}10307 \\
110\end{array}$ & $\begin{array}{c}10816 \\
992\end{array}$ & $\begin{array}{c}10507 \\
724\end{array}$ & $\begin{array}{l}1088 \\
6172\end{array}$ & $\begin{array}{c}11056 \\
814\end{array}$ & - \\
\hline Bulgaria & 152766 & 177936 & 173917 & 177553 & 199083 & 192357 & $\begin{array}{c}23538 \\
6\end{array}$ & $\begin{array}{c}2588 \\
56\end{array}$ & $\begin{array}{c}32200 \\
4\end{array}$ & - \\
\hline
\end{tabular}

Source: Eurostat

By the trend presented in fig. 1 there is a clear growing use of inorganic fertilizers on the territory of our country. It has more than doubled for the period 2006-2014, towards its end reaching 322 million tons. In the EU, the increase is insignificant for the same period, with only $2,2 \%$. There is a faster increase in the amount of mineral fertilizers used in Bulgaria than in the Union as a whole. The forecast made for post-consumer consumption shows a clear trend indicating an increasing amount of imported fertilizers.
The increase of the total quantities of imported mineral fertilizers in agriculture increases not only due to an increase in the arable land, but also for the period 2005-2014 according to data of Bulgarian Food Safety Agency (BFSA) for the territory of the country, increased fertilization norms were reported by about $61 \%$ as the average increase in fertilization rates per 1 hectare is about $6 \%$ on an annual basis (Table 2).

Table 2. Used mineral fertilizers $(\mathrm{kg} / \mathrm{ha})$ in agriculture in relation to the utilized agricultural area

\begin{tabular}{|l|c|c|c|c|}
\hline Year & Total fertilizers & Nitrogen & $\mathbf{P}_{\mathbf{2}} \mathbf{O}_{\mathbf{5}}$ & $\mathbf{K}_{\mathbf{2}} \mathbf{O}$ \\
\hline 2005 & 35,8 & 30,2 & 4,7 & 0,7 \\
\hline 2006 & 35,8 & 29,4 & 4,8 & 1,5 \\
\hline 2007 & 43,2 & 34,7 & 5,7 & 2,6 \\
\hline 2008 & 42,6 & 34,1 & 6,0 & 2,54 \\
\hline 2009 & 43,7 & 35,3 & 6,1 & 2,3 \\
\hline 2010 & 51,2 & 39,4 & 7,7 & 4,1 \\
\hline 2011 & 46,4 & 37,8 & 5,8 & 2,8 \\
\hline 2012 & 59,9 & 45,9 & 9,3 & 4,6 \\
\hline 2013 & 61,1 & 51,8 & 5,3 & 3,9 \\
\hline 2014 & 57,8 & 41,7 & 11,7 & 4,4 \\
\hline
\end{tabular}

Source: BFSA

The implementation of high fertilization standards implies the achievement of higher production results needed to tackle the food problem, but contrary to the data of Ministry of Agriculture and Food (MAF)intensification of agricultural production, despite the higher production inputs, the average yields of the crops vary on an annual basis change, also showing negative values (Table 3).

Table 3. Change in average yields of basic crops

\begin{tabular}{|lcccccc|} 
Year & 2013 & 2014 & 2015 & 2014 & 2015 & 2016 \\
& & Average yield (kg/ha) & & $\begin{array}{c}\text { Annual change on \% basis } \\
\text { compared to the previous year }\end{array}$ \\
\hline Sunflower & 224 & 238 & 209 & $6,2 \%$ & $-12,2 \%$ & - \\
\hline Corn (grain) & 639 & 768 & 541 & $20,2 \%$ & $-29,5 \%$ & - \\
\hline Wheat & 418 & 422 & 453 & $0,9 \%$ & $7,3 \%$ & - \\
\hline Rye & 188 & 195 & 178 & $3,7 \%$ & $-8,7 \%$ & - \\
\hline Barley & 369 & 397 & 397 & $7,5 \%$ & $0 \%$ & - \\
\hline
\end{tabular}


Agriculture and its concomitant activities are seen as one of the biggest pollutants stemming precisely from modern conventional agriculture. The pollution from agrarian production is not limited only to lowering the quality of groundwater and soils under the influence of mineral fertilization but also to air pollution with greenhouse gas emissions. Table 4 presents data on reported greenhouse gas emissions from agricultural production during 2010-2014:

Table 4. Reported quantities of greenhouse gas emissions from agriculture for 2010-2014

\begin{tabular}{|lccccc|}
\hline \multicolumn{1}{|c}{ Years } & $\mathbf{2 0 1 0}$ & $\mathbf{2 0 1 1}$ & $\mathbf{2 0 1 2}$ & $\mathbf{2 0 1 3}$ & 2014 \\
$\begin{array}{l}\text { Total EU-28 emissions } \\
\text { (in mil.t.) }\end{array}$ & 426.93907 & 426.94564 & 424.39267 & 428.0687 & 434.9377 \\
\hline $\begin{array}{l}\text { Total emissions } \\
\text { Bulgaria }\end{array}$ & 5.31884 & 4.95957 & 5.04014 & 5.50179 & 5.09229 \\
\hline
\end{tabular}

Source: Eurostat

As a country of the United Nations Framework Convention on Climate Change (UNFCC), Bulgaria has an obligation to conduct annual greenhouse gas inventories. The share of the main sources of greenhouse gases by causes for 2014 is as follows in Figure 2: (3)

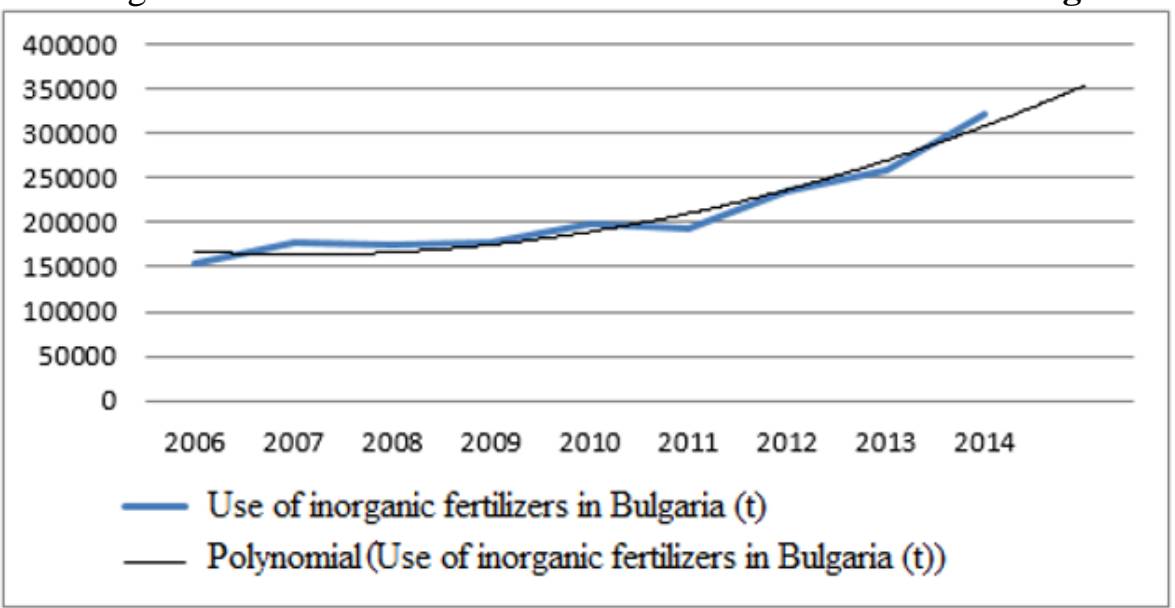

Fig. 1 Use of inorganic fertilizers in Bulgaria 2006-2014
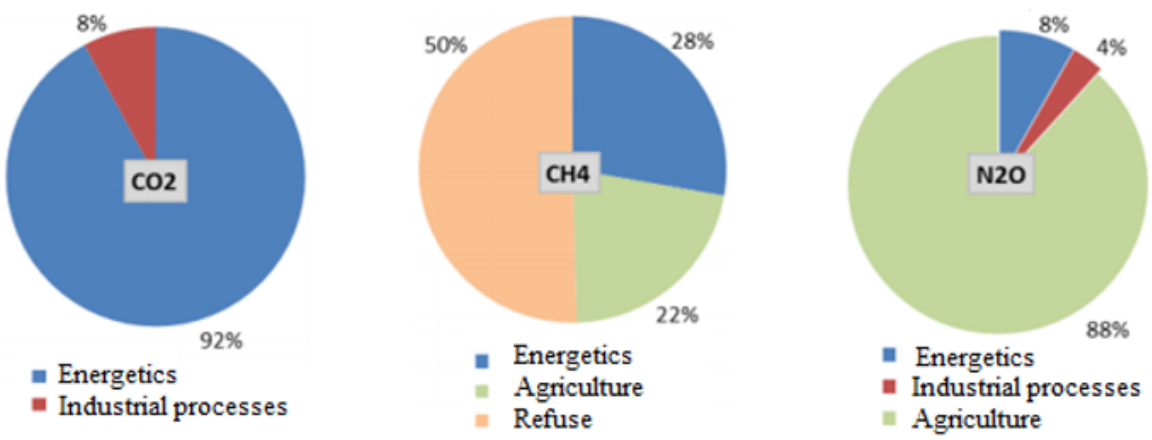

Fig.2. Share of the main sources of greenhouse gases by causes for 2014 (3)

The emissions from the greenhouse gases from sector "Agriculture" result precisely from the activities and processes of working and processing of agricultural production, soil fertilization and treatment of the animal waste. The processes from the sector's activities are mainly sources of $\mathrm{CH}_{4}$ and $\mathrm{N}_{2} \mathrm{O}$ pollutants. The largest source of $\mathrm{CH}_{4}$ emissions in the sector is the enteric fermentation at farm livestock or $29 \%$ of the sector's emissions, while the largest share of $\mathrm{N}_{2} \mathrm{O}$ emissions is from agricultural soils, their share in 2014 is $54 \%$ (3). The legislation in Bulgaria prohibits the burning of plant residues from the stubbles, this activity still exists and it is a source of greenhouse gases and derivatives of $\mathrm{CO}$ and Nox greenhouse gases precursors (Figure 3). 

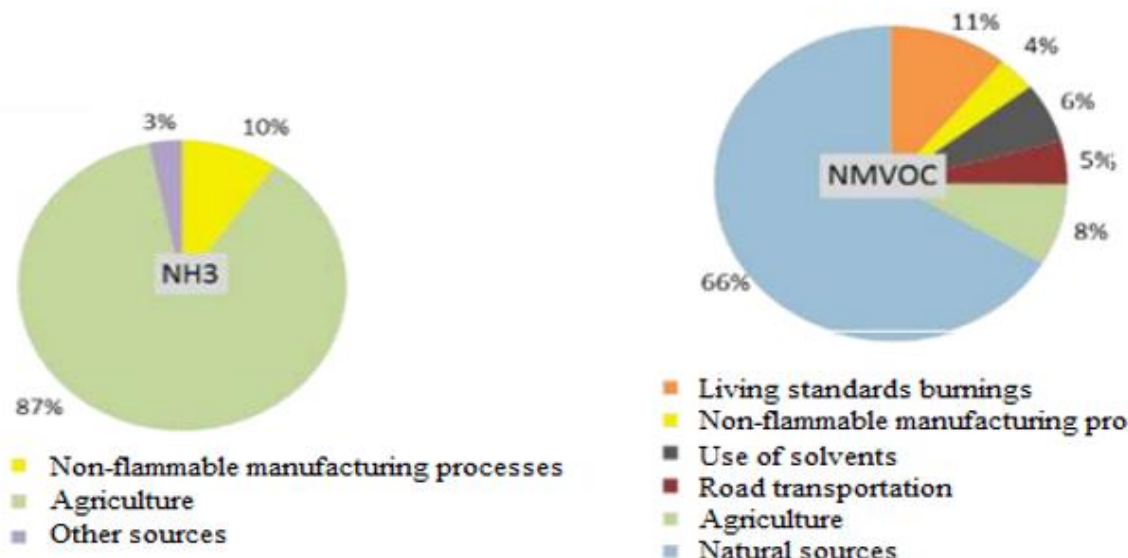

Living standards burnings

Non-flammable manufacturing processes

- Use of solvents

- Road transportation

II Ariculture

* Natural sources

Fig.3. Distribution of the share of emissions of harmful substances in 2014

Out of the data on the released greenhouse gas emissions in the atmosphere by the agricultural production activities, there is no clear tendency of their quantities reducing which is related to Bulgaria's commitment to achieving the targets under Kyoto Protocol. According to the data on the progress towards achieving the Strategy „Europe 2020" and Kyoto Protocol from the REPORT FROM THE COMMISSION TO THE EUROPEAN PARLIAMENT AND THE COUNCIL on the progress of the climate action, there are data which clearly show a failure to meet Bulgaria's targets for Reducing greenhouse gas emissions, as for 2014, our country is at $-12 \%$ non-fulfillment of the values compared to the base year 1990, and with $-25 \%$, respectively, the default of the estimated values for 2020. These negative projections can be increased by lowering greenhouse gas emissions from agriculture that could be reached by reducing the amount or wholly replacing synthetic fertilizers and preparations with organic ones. The highest values of the quantities of gases from the activities in the agrarian production are related to the energy consumption of the sector for fertilizer production and their bringing into the soil (Figure 4).

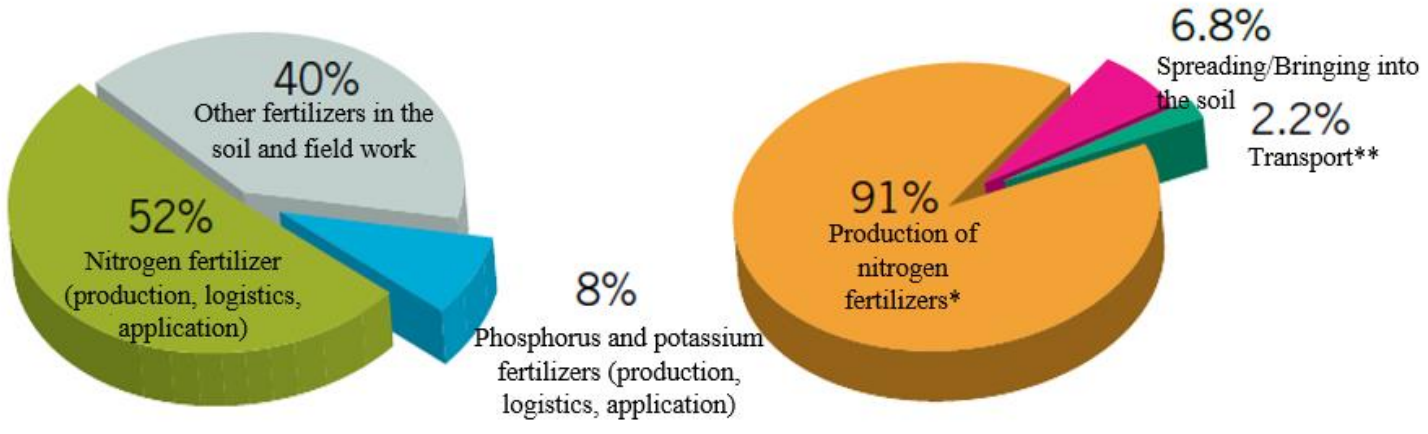

* Including energy used for the extraction and transportation of fossil fuels to the $\mathrm{N}$ fertilizer factory (average value for all $\mathrm{N}$ fertilizers)

** Transport of $\mathrm{N}$ fertilizer at a distance of $400 \mathrm{~km}$ by ship and truck ( $1 \mathrm{GJ}=25$ liters of oil)

Fig.4. Energy consumption in the agricultural sector (6)

2. Potential and ways of utilization of residual biomass from agricultural activities.

The utilization of waste biomass in agriculture is one of the ways to deal with the environmental situation created by anthropogenic activity. As sources of biomass obtaining, the most commonly used are namely the plant waste from agriculture and forestry as well as the food industry, pulp production; wood waste (excluding those containing halogenating organic compounds or heavy metals), animal substances, cork waste, sludges from purification plants. The biomass is considered to be a future key renewable resource driven by the rapid depletion of fossil fuels, as well as population growth and the consumption per head. One of the main advantages of biomass is its agroeconomic importance, as its use stimulates the economic development of the countries along with helping to reduce the greenhouse effect and for the fight against the climate change. The most important benefits associated with the use of biomass are: increasing of the farm incomes and diversifying of markets, along with 
reducing surpluses from agricultural production, limiting of harmful environmental impacts, etc. An emphasis is placed on the environmental friendliness of biomass utilization during the realization of the economic performance for agriculture. Some significant amount of biomass generated by farm crop and livestock cultivation, waste storage, maintenance of green areas in the public sector or wastewater treatment is such a source of raw material, the quantities of which are considered to be an inexhaustible source of energy. The potential of biomass (Table 5) is enormous, and when it is not being used there is a decomposition process, this decomposition causes methane that overburdens the environment, which is a factor in creating the greenhouse effect.

Table 5. Potential of biomass in Bulgaria (7)

\begin{tabular}{|c|c|c|c|}
\hline \multirow[t]{2}{*}{ Type of waste } & \multicolumn{3}{|c|}{ Potential } \\
\hline & Total & ktoe* & $\%$ \\
\hline Wood & 1110 & 510 & 46 \\
\hline Wastes from the industry & 77 & 23 & 30 \\
\hline Agricultural plant residues & 1000 & 1000 & 100 \\
\hline Agricultural animal remains & 320 & 320 & 100 \\
\hline Landfill gas & 68 & 68 & 100 \\
\hline Rapeseed oil and waste oils & 117 & 117 & 100 \\
\hline Total: & 2692 & 2038 & 76 \\
\hline
\end{tabular}

* toe - petroleum equivalent 1 toe $=11.63 \mathrm{MWh}$, non-standard energy unit

From the data of the unused potential, the conclusion is drawn that the country needs to take action on the utilization of both residual and those polluting the environment waste raw materials from agricultural activities. The utilization of biomass for agricultural purposes is itself mainly used for the production of organic fertilizers of plant or animal origin, with each ton of rotten enough and properly preserved manure in the soil are spread about 200-300 kg. organic substance, 5-6 kg. nitrogen, $2-3 \mathrm{~kg}$. phosphorus, $5-6 \mathrm{~kg}$. of almost all trace elements. The compost is another type of organic fertilizer produced by the utilization of residual biomass, as the effect of adding compost is immediate but also with a very long-term positive impact on the soil structure and it does not become firm and this leads to increased water/moisture retentive capacity, and subsequently leads to a reduction of the farm costs for soil irrigation. Soil fertilizers can also be used to enrich the soil with organic matter called siderates. These siderates are another type of organic fertilizer in which the above-ground green and juicy parts and the roots of plants are plowed into the soil in order to increase soil fertility. The advantage of green fertilization in comparison with manure is its low cost, the materials and labor costs associated with the growing of the green fertilizers are smaller than those for the preparation and introduction of manure in the soil.

The advantages of using residual biomass in modern agricultural production are associated with the sustainable production. To address a number of these issues, namely lowering farm production costs, reducing the negative impact of intensive production, and including waste from the production process back into it here as a complex solution, biogas production can be considered. Biogas is a biofuel in gaseous form, which is produced by organized fermentation in anaerobic soils, i.e. without the presence of oxygen medium. The raw materials for biofuel production are organic waste of plant and animal origin. At biogas production the emissions of methane $\left(\mathrm{CH}_{4}\right)$ and nitrous oxide $\left(\mathrm{N}_{2} \mathrm{O}\right)$ that release in storage and use of manure for fertilization are reduced. The greenhouse effect of methane is 23 times, and nitrous oxide 296 times higher than carbon monoxide, and the production and use of biogas contributes to the saving of these emissions and limiting the global warming (8). One of the most significant benefits of biogas production is the use of residual raw material from agricultural production and its transformation into a valuable resource. Biogas technologies contribute to reducing the volume of waste and the cost of its utilization. Another significant advantage at biogas production is that, compared to the use of imported fuels, the production of biofuels requires much more labor for the production, collection and transportation of raw materials for the production of technical equipment, and the construction, operation and maintenance of biogas installations, etc. At biofuels production the least amount of water compared to other biofuels is being used. Biofuel installations are economically attractive for farmers due to the fact that biofuel production can take place in 
co-generation installations for the production of heat and electrical energy that farms can use to meet their own needs or sell green energy at preferential prices to the state. In addition to energy producing from farm waste, a high quality liquid fertilizer as a residual product from biogas production is obtained and it is used without its necesity of being rotten. Farms reduce their own energy production costs, high-quality manure, which can also bring extra farm income.

In order to limit the negative impacts of anthropogenic activity and the intensification of agricultural production, more and more deeds are being set from the concepts of sustainable development of agriculture and the practice of agri-environmental practices, including environmental protection and achieving economic performance for the agricultural manufacturer.

3. Conceptual model of a dairy cow farm producing biogas in a cogeneration installation for heat and electricity.

A conceptual model of a livestock farm (dairy cow farm) in the town of Tvarditsa, kv. Kozarevo, producing biogas, is presented to outline the practical effects of the biogas installation. In the investment project of the farm for the construction of a fertilizer site, the quantities of expected raw materials were calculated (for the year 2016, the farm recorded an increased number of bred animals and the data was recalculated), as shown in Table 6:

Table 6. Expected quantities of fertilizer produced in the farm *

\begin{tabular}{|c|c|c|c|c|c|c|c|}
\hline \multirow[t]{2}{*}{ Cattle category } & \multirow{2}{*}{$\begin{array}{c}\text { Num } \\
\text { ber }\end{array}$} & \multicolumn{2}{|c|}{ Daily per head } & \multicolumn{2}{|c|}{ Daily for all animals } & \multicolumn{2}{|c|}{ Total for a year } \\
\hline & & $\begin{array}{c}\text { Manure } \\
\text { (kg.) }\end{array}$ & $\begin{array}{c}\text { Bedding } \\
\text { (kg.) }\end{array}$ & $\begin{array}{c}\text { Manure } \\
\text { (kg.) }\end{array}$ & $\begin{array}{c}\text { Bedding } \\
\text { (kg.) }\end{array}$ & $\begin{array}{c}\text { Manure } \\
\text { (kg.) }\end{array}$ & $\begin{array}{c}\text { Bedding } \\
\text { (kg.) }\end{array}$ \\
\hline Cows (dairy) & 87 & 52 & 1,7 & 4524 & 148 & 1651260 & 54020 \\
\hline $\begin{array}{l}\text { Calves and young } \\
\text { buffalos over } 1 \\
\text { year old for } \\
\text { breeding and } \\
\text { pregnant heifers }\end{array}$ & 8 & 4,8 & 0,2 & 38 & 1,6 & 13870 & 584 \\
\hline $\begin{array}{c}\text { Calves and young } \\
\text { buffalos over } 1 \\
\text { year and under } 2 \\
\text { years old for } \\
\text { fattening }\end{array}$ & 4 & 0,4 & 0,04 & 1,6 & 0,16 & 584 & 58 \\
\hline $\begin{array}{l}\text { Calves and young } \\
\text { buffalos up to } 1 \\
\text { year old. }\end{array}$ & 22 & 2,2 & 0,2 & 48 & 4,4 & 17520 & 1606 \\
\hline All: & 121 & 59,4 & 2,14 & 4611,6 & 154,16 & 1683234 & 56268 \\
\hline & & & & & Total & 173950 & g/year \\
\hline
\end{tabular}

* The data are recorded with approximate values

Source: Investment project "Fertilizer site of a Dairy farm"

The investment project stated that the dairy farm will have $750 \mathrm{~m} 3$ of manure per year for 110 animals, or about $850 \mathrm{~m} 3$ for 121 heads a year. In relation to the production of biogas and electricity and heat, the biogas and calorific value of incoming substrates are shown in Table 7.

Table 7. Data on biogas yield and calorific value of input substrates based on $1739.5 \mathrm{t} / \mathrm{yr}$. cattle dung

\section{CONTENTS}

1. DRY SUBSTANCE (CB) - \% IN FRESH MASS (CBM)

2.CB INCL. ORGANIC (OCB) - \% IN CB

3. BIOGAS YIELD - L/KG OCB

4. BIOGAS YIELD $-\mathrm{M}^{3} / \mathrm{T}$ CBM

5. METHANE CONTENT - VOL.\% IN BIOGAS

CALORICITY

6. BIOGAS - NM ${ }^{3} / \mathrm{T}$

INCLUDING METHANE NM ${ }^{3} / \mathrm{T}$

7. BRUTO E - KWH/T

8. BIO FERTILIZER

*Own calculations
CATTLE DUNG WITH BEDDING

\section{3,95 т. $(10 \%)$}

1391,6 т. $(80 \%)$

1078,49 л.

$86,28 \mathrm{~m}^{3}$

55

$52880 \mathrm{Nm}^{3}$

$29084 \mathrm{Nm}^{3}$

$289971 \mathrm{kwh}$

1669,9 т. 
A total of $822,8 \mathrm{~m}^{3}$ of manure per year (about $2,25 \mathrm{~m}^{3}$ / day) is obtained from the cow farm in Kozarevo so with these available raw materials the farm can produce $5,4 \mathrm{~kW}_{\mathrm{el}} /$ per day $(10,8$ $\mathrm{kW}_{\mathrm{el}} /$ per one day and night) (9). Due to the low capacity of the biogas installation, it is of no interest for the cow farm to sell its produced electricity and heat. In such a situation it is necessary to consider whether the production of biogas and energy cogeneration is effective for the cowherd farm to cover its own needs. The volume of biogas production that is generated depending on the type of substrate used, and namely livestock manure from Cattle and the daily amount of raw materials (Table 7) is as follows biogas yield of $1 \mathrm{~kg}$. excrements from Cattle with 80\% moisture equals 0.04-0.05 m3 / $\mathrm{kg}$ and the farm realizes $86975.1 \mathrm{~m} 3$ of biogas. For the breeding of a head ЕРД/ Cattle, about 1$1.1 \mathrm{~m}^{3} /$ per day of biogas is needed. The breeding of 121 heads of Cattle requires at about $133 \mathrm{~m}^{3} /$ per day of biogas and $48545 \mathrm{~m} 3$ per year. From the data presented, it can be seen that the farm can cover its own electricity and heat production needs, and the sale of the realized bio fertilizer of $1669.9 t$ to the organic crop farms can add an extra income to the cow farm activities. The realized residual high-quality bio fertilizer is characterized with a content of $1 \mathrm{~m} 3$ of fertilizer per $5 \mathrm{~kg}$. nitrogen $1.5 \mathrm{~kg}$. phosphorus and $4 \mathrm{~kg}$. potassium.

In 2016 the livestock farm is applied for a technology project to build a "Forage production system". The modular equipment is a system which works on the principle of the hydroponics system, with a daily amount of material being loaded into the system, for example - barley, which grows for 7 days and becomes on greenleaved sods with a height of 15 to $20 \mathrm{~cm}$. Out of $1 \mathrm{~kg}$ of grain in the system there is obtained from 6 to $10 \mathrm{~kg}$. green mass - forage with high energy and easily digestible. The installation greatly improves the amount of milk and ensures a constant yield of milk without peaks and dips, while at the same time is improving the immune system of the animals. For the maintenance of the system a daily water consumption of 750800 liters and power of $9.5 \mathrm{~kW}$ are required. After the above mentioned about the capacity of the farm for own electricity and heat production, it also is taken into account the ability of the cow farm to cover its own needs for the operation of the animal forage system from its waste material. The application of this agroecological practice leads to a reduction in the cost of the cow farm as well as a positive impact on the environment with reduced emissions from the livestock farm. In addition to reduced costs, the farm can add income to its business with the realization of the residual bio fertilizer.

\section{CONCLUSION}

Modern agricultural activity is characterized by a proven negative impact on the environment, its production resources as well as on the exhaustible resources. The intensification of agricultural activity exhausts its production resources, such as soils, waters, and influences climate change. All of these factors have a reciprocal effect on production expectations, so that the food needs of the progressively growing population can be met. With such destructive actions, modern agricultural production continues with aggressive measures to increase the benefits of production by increasing the quantities of chemical fertilizers and preparations produced, polluting the air, and subsequently polluting soils after their input into ever higher rates. At the same time, large quantities of waste materials are also generated from the activity of agrarian production, upon their utilization the farmer can cut part of the permanent expenses and also make additional profits.

The ecologisation of agricultural production and the return of its waste materials back into production is key to the more sustainable development of the sector. The utilization of production residues reduces the negative impact of the anthropogenic activity towards the environment, brings additional dividends to producers, and also increases the industry's empathy to our country's commitment to the Kyoto Protocol.

\section{REFERENCES}

1. I. Georgiev, M. Manolov. Ecology and sustainable development. unknown.: Economy, 1999.

2. 2.B. Zaharinov, N. Kolev. State of the soil monitoring in Bulgaria. 2010, 3-4.

3. Ministry of Environment and Water, Executive Environment Agency. National Report on the Status and Protection of the Environment. Sofia: unknown, 2016.

4. Agricultural sustainability and intensive production practices. David Tilman, KennethG. Cassman, Pamela A. Matson, Rosamond Naylor \& Stephen Polasky. unknown.: Nature Publishing Group, 2002, Vol. 418.

5. European Environment Agency. European environment. State and perspectives 2015. 2015.

6. Europe, Sustainable agriculture in. Harvesting energy with fertilizers. 2011. 
7. Ministry of Economy and Energy, Agency for Energy Efficiency. National Long-Term Program to Promote the Use of Renewable Energy Sources 2005-2015. Sofia: unknown.: 2005.

8. Stanev, S. Biogaz - The energy that comes from the sun and accumulates in the plants.
9. Teodorita Al Seadi, Dominik Rutz, Heinz Prassl, Michael Köttner, Tobias Finsterwalder, Silke Volk, Rainer Janssen, Denitsa Dimitrova, Iva Cheriyska. Biogas Handbook. 2009. 